\title{
XCII. Experiments relative to the action of hydrochloric acid upon mixtures of tin and antimony
}

\section{Chaudet}

To cite this article: M. Chaudet (1817) XCII. Experiments relative to the action of hydrochloric acid upon mixtures of tin and antimony, Philosophical Magazine Series 1, 49:230, 402-405, DOI: $10.1080 / 14786441708637935$

To link to this article: http://dx.doi.org/10.1080/14786441708637935

电 Published online: 27 Jul 2009.

Submit your article to this journal $\pi$

Џll Article views: 2

Q View related articles $₫$ 
excepting the Newcastle coal-strata, which was from information and sections sent me from my friend Mr. Thomas Fenwick of Dipton.

I beg leave further to add, that I hope Mr. Winch will allow that mine is the first attempt to form a connexion between the Newcastle coal and the metalliferous limestone formations; which I trust on examination will be found to be an approximation to truth.

By inserting the above in your valuable Magazine, you will much oblige,

Sir, your most obedient,

Garrigill Alston Moor, May 27, 1817.

Westgarth Forster.

XCII. Expsriments relative to the Action of Hydrochloric Aid upon Mixlures of Tin and Antimony. By M. ChaudeT*. $T_{H B}$ very lively action which hydrochloric acid exerts when brought in contact with tin, compared with the almost insensible influence which it has upon antimony, led M. Thenard to think that it might be employed as a means of separating these two metals when found in union; but the experiments which he made, with this object, were not attended with the success he anticipated.

Having procured tin and antimony in as pure a state as possible, I began by examining the action of hydrochloric acid on these two metals taken separately.

I flattened, to about the thickness of a centime, a portion of the tin, and put it into a phial, into which 1 afterwards introduced a certain quantity of hydrochloric acid perfectly pure, the specific weight of which was 1190 , and which marked $22^{\circ}$ on an areometer of Baumés. At the end of six hours the dissolution was perfectly complete.

On applying a slight boiling heat to the same mixture, the dissolution was completed in one hour.

I then pounded 100 parts of antimony to a fine powder, and put them into a phial with a quantity of hydrochloric acid. After remaining twenty-four hours in a cold place, I found that 96 parts of the antimony remained at the bottom of the vessel, and that only four parts had dissolved $\uparrow$.

A like

* From the Anmales de Chimie et de Physique for December 1816.

+ After being some hours in the glass, the liquor which was at first white became yellowish. On shaking the glass this colour disappeared, but returued in a few hours after: the glass being again shaken, the colour again disappeared; -and as often as the same operation was rejeated a like resuit

followed. 
A like mixture being set to boil, a similar proportion of four parts of antimony was found dissolved at the end of three hours.

The dissolution of these four parts in both cases appeared to be greatly owing to the presence of sulphuret of antimony in the antimony employed, a slight disengagement of sulphuretted hydrogen gas having been observed during the dissolntion.

I next made two mixtures; one contiaining equal parts of tin and of antimony, and another 25 parts of antimony and 75 of tin.

The first of these mixtures, though harder than antimony, was so brittle that it broke on falling to the ground, and was very easily reduced to a fine powder. Its specific weight, estimated with much care, was found to be $6 \cdot 803$, the water distilled forming 1 .

The second mixture, the specific weight of which was found to be $7 \cdot 059$, was first flattened with a hammer and then slightly chopped. It was easy to perceive that the tin had, with the smaller proportion of antimony here combined, already lost somewhat of its ductility.

The following are the experiments which I made on these mixtures :

First Experiment. One hundred parts of the first mixture, containing equal parts of tin and antimony, with an equal proportion reduced to a fine powder, were heated and treated with hydrochloric acid:- the action seemed very slight; the metal preserved its whiteness and its metallic brilliancy. After about three hours of ebullition $I$ filtered the mixture, and found that 33 parts of the metal had been dissolved.

Second Experiment. One hundred parts of the second mixture, containing twenty-five parts of antimony and seventy-five of tin, after being beaten very thin, were heated and treated with hydrochloric acid. The action was much greater than in the preceding experiment; the metal from being perfectly white became slightly browned. After an hour of ebullition, no increase of action appearing, I filtered, and found that 53 parts of the metal had been dissolved.

From these two experiments it was easy to see that the antimony, besides being itself nearly insoluble in the hydrochloric acid, served to counteract the dissolution of the tin; and that in proportion as there was less of antimony in the mixture, there was more of the tin dissolved.

followed. This yellow colour is undoubtedly owing to a certain quantity of chlorine, formed at the expense of the oxygen of a part of the water decomposed, and which from its tendency to a gaseous state disengages itself on the agitation of the liquid.

C c 2 


\section{Experiments with Hydrochloric Acid upon Tin, Bi.}

On recalling to mind the process which is used to extract by means of nitric acid the silver contained in gold, and the necessity there is in that case of emploving three parts of silver to one of gold - a process commonly known by the name of quartation, -it occurred to me that tin might be to antimony as siver is to gold, and that the proportion of tin necessary to the quartation of antimony ought to be much greater than what I had used in the preceding experiments, - that this only reguired to be sought after to be ascertained. I accordingly made the following experiment:

Third Experiment. I weighed with great care, in a balauce capable of indicating the very nicest proportions, ten parts of antimony and 90 parts of tin, being as nine to one. I enveloped the whole in a piece of paper, placed it in the bottom of a small experimenting crucible, covered it with a layer of fine powder of charccal, in order to prevent oxidation, and subjected it to the heat of an essay furnace for ten minutes. I then withdrew the crucible from the fire, and allowed it to cool. On examining it I found a small drossy mass, which I first brushed carefully, then flattened, and afterwards cut into a nmmber of pieces. I wrapped tip these anew in paper, and subjected them to the heat of the stove in the same manner as before. The mixture being again cooled and well brushed, was without being flattened fused a third time, and only a very small slip of paper interposed between it and the charcoal. The residue which I now obtained consisted of a small compact knob, of metallic brilliancy, and exactly 100 parts in weight. I flattened this as thin as I could, and cut it with scissars into small fragments, which 1 put into a phial and afterwards saturated with hydrochloric acid. Having boiled the whole for two hours, I allowed it to cool, and then collected upon a filter the portion not dissolved. I found it to be of the weight of twelve parts in place of ten.

Fourth Experiment. 1 joined with the same carc as in the preceding experiment, five parts of antimony to 100 of tin, being as 1 to 20 . The knob obtained as before, being lattened as thin as possible, cut into pieces, and these put into glass; I saturated them with hydrochloric acid. The action was quicli, and at the end of a quarter of an hour tlie dissolution appeared almost complete. The antimony abstracted floated in the liquor: I made it-still boil for two hours longer; and on then collecting the residue on a filter, I found just five parts of antimony-being the precise quantity which I had put into the mixture.

On repeating this experiment, I obtained exactly the same result. 
1 made a similar one with 15 parts only of tin in place of 20 to one of antimony, and found a surplus.

In another experiment, with the tin in the proportion of $\mathbf{3 0}$ to one, the result gave me back exactly the proportion of antimony put into the mixture.

I last of all put only a centime, and afterwards the fourth of $a$ centime of antimony to 100 parts of tin, and recovered them perfectly.

The antimony in these different experiments was extremely divided, of a blackish gray colour, settled easily at the bottom of the vessel, and occupied, in proportion to its weight, a very considerable space; so as to enable even imponderable quantities to be discemed.

It is after all very true, that antimony as well as tin is soluble in hydrochloric acid, and that its presence was not indiscernible in the hydrochlorate of tin produced in the fourth experiment. But this I think may be easily reconciled with the truth-of the preceding results. The hydrochlaric acid having a remarkable affinity to tin, woułd of course saturate it first, and_thus lose almost entirely its power of acting on the antimony. It is hard to believe that any tin can remain in alliance with the antimony, when we find the different residues corresponding so exactly with the quantities of antimony introduced; and much more probable that the portion of antimony observable in the hydrochlorate of tin, may be a portion not appreciable by weight.

As it often happens that lead is joined to the tin already united with the antimony, I made an experiment in order to ascertain at what point this new metal might be able to change the results obtained by my preceding mode of analysis; and $I$ perfectly satisfied myself that the nix ture of tin and antimony may contain large enough ciuanfities of lead without affecting the success of the operation.

XCIII. On the Cultivation of the Parsnip, as it $j$ s practised in Guernsey. By Dr. Macculdoch, of Wionlewioh

The great superiprity of this root, as cultivated in Guernsey and the neighbouring islands, to its produce in Britain, - the high reputation which it bears among the farmers in those is!ands, and the very little knowledge of it, which those of Britain seem to possess, - have induced me to lay before the Society a short account of the methods practised in its culture in Guernsey.

I am inclined to think, that it will be found much more worthy the attention of agriculturists than has been hitherto supposed,

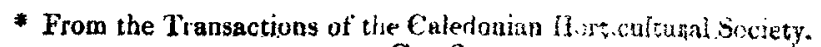

C c 3 and 